\title{
Table of national legislation
}

\section{CAMBODIA}

Law on the Establishment of the

Extraordinary Chambers in the

Courts of Cambodia 2004, NS/

RKM/1004/006 408

\section{CANADA}

Crimes Against Humanity and War

Crimes Act, SC 2000 115

\section{GIBRALTAR}

Judgments (European Community)

(Enforcement) Act 1973, Act

1973-19 286,291

\section{JAMAICA}

Caribbean Court of Justice (Original

Jurisdiction) Act 2005 291

\section{MALTA}

European Communities (Enforcement of International Judgments) Order 2007, LN 389 of 2007 .... 286, 291

\section{UK}

European Communities (Enforcement of Community Judgments) Order, SI 1972/1590 286, 291

\section{IRELAND}

European Communities (Enforcement

of International Judgments,

Orders and Decisions)

Regulations, SI 121 of 2007 .. 286, 
William A. Schabas and Shannonbrooke Murphy - 9781781005026 Downloaded from PubFactory at 04/26/2023 09:43: ๑०AM via free access 